\title{
Iowa satisfaction with anesthesia scale
}

\section{To the Editor:}

I was gratified to learn that Dr. Kim and colleagues found the Iowa Satisfaction with Anesthesia Scale [1] useful for comparing patient satisfaction between dexmedetomidine and propofol/alfentanil groups during cataract surgery [2]. Fung and colleagues found reliability and validity for cataract surgery patients among English speaking patients [3]. A recent multicenter center showed reliability and validity when used by telephone with English-speaking patients [4]. In English, there is a clear distinction between the somatic "I felt pain" and emotive "I hurt." Is this true in Korean? If respondents could not understand the meaning of "I hurt," then the internal consistency of the 11 items would be lower than the Cronbach alpha of 0.84 (95\% confidence interval, $0.79-0.87$ ) from the multicenter study [4]. If "I hurt" and "I felt pain" were not distinguishable, responses would be the same for nearly all patients, unlike the $39 \%$ giving different scores from the multicenter study [4].

\section{Franklin Dexter}

Departments of Anesthesia and Health Management \& Policy University of Iowa, Iowa City, IA, USA

E-mail: franklin-dexter@uiowa.edu

\section{References}

1. Dexter F, Aker J, Wright WA. Development of a measure of patient satisfaction with monitored anesthesia care: the Iowa Satisfaction with Anesthesia Scale. Anesthesiology 1997; 87: 865-73.

2. Na HS, Song IA, Park HS, Hwang JW, Do SH, Kim CS. Dexmedetomidine is effective for monitored anesthesia care in outpatients undergoing cataract surgery. Korean J Anesthesiol 2011; 61: 453-9.

3. Fung D, Cohen M, Stewart S, Davies A. Can the Iowa Satisfaction with Anesthesia Scale be used to measure patient satisfaction with cataract care under topical local anesthesia and monitored sedation at a community hospital? Anesth Analg 2005; 100: 1637-43.

4. Dexter F, Candiotti KA. Multicenter assessment of the Iowa Satisfaction with Anesthesia Scale, an instrument that measures patient satisfaction with monitored anesthesia care. Anesth Analg 2011; 113: 364-8.

\section{In Response:}

We thank Dr. Franklin Dexter for his comments on our study. The problem about the reliability and validity of Iowa Satisfaction with Anesthesia Scale (ISAS) [1] are important things as he concerned. Before starting this study [2], we translated the ISAS into Korean with the help of bilingual English/Korean speaker and native English speaker. At that time, of course, we made every effort to express subtle differences in the meaning of some expressions, such as "I felt pain" and "I hurt" that he mentioned. Before we got his comments, we had not actually thought about the problem of reliability and validity so seriously. Although we did not verify reliability and validity of the Korean version of ISAS, we believe that it would work in Korean as well. Finally, we would like to thank Dr. Dexter and the University of Iowa Research Foundation for the permission of use of the ISAS.

Hyo-Seok Na, In-Ae Song, Hong-Sik Park, Jung-Won Hwang, Sang-Hwan Do

Department of Anesthesiology and Pain Medicine, Seoul National University Bundang Hospital, Seongnam, Korea

\section{Chong-Soo Kim}

Department of Anesthesiology and Pain Medicine, Boramae Medical Center, Seoul, Korea

E-mail: cskim@brm.co.kr

\section{References}

1. Dexter F, Aker J, Wright WA. Development of a measure of patient satisfaction with monitored anesthesia care: the Iowa Satisfaction with Anesthesia Scale. Anesthesiology 1997; 87: 865-73.

2. Na HS, Song IA, Park HS, Hwang JW, Do SH, Kim CS. Dexmedetomidine is effective for monitored anesthesia care in outpatients undergoing cataract surgery. Korean J Anesthesiol 2011; 61: 453-9. 